\title{
CSTNPD: A Database for Cancer Specific Toxic Natural Products
}

\author{
Mohammad Ajmal Ali', Mohammad Tabrez Quasim ${ }^{2 *}$, Mohammad Abul Farah ${ }^{3}$, Fahad Moham- \\ mad Al-Hemaid' ', Joongku Lee ${ }^{4}$, Khalid Mashay Al-Anazi ${ }^{3}$, Soo Yong Kim ${ }^{5}$ and Tapan Pan ${ }^{6}$ \\ 'Department of Botany and Microbiology, College of Science, King Saud University, Riyadh- 11451, Saudi Arabia; \\ ajmalpdrc@gmail.com, fhemaid@ksu.edu.sa \\ 2Department of Computer Science, College of Computing \& Information Technology, University of Bisha, Bisha - \\ 61361, Saudi Arabia; mtabrez@ub.edu.sa, \\ 32Department of Zoology, College of Science, King Saud University, Riyadh- 11451, Saudi Arabia; farahabul@gmail. \\ com, kalanzi@ksu.edu.sa \\ ${ }^{4}$ Department of Environment and Forest Resources, Chungnam National University, 99 \\ Daehak-ro, Yuseong-gu, Daejeon 34134, Republic of Korea; joongku@cnu.ac.kr \\ International Biological Material Research Center, Korea Research Institute of Bioscience and Biotechnology, Dae- \\ jeon- 305 806, Republic of Korea; soodole@kribb.re.kr \\ ${ }^{6}$ University Department of Botany, Tilka Manjhi Bhagalpur University, Bhagalpur - 812007, Bihar, India; tkpan. \\ botany@gmail.com
}

\begin{abstract}
Objective: To compile an open access central resource database for cancer specific toxic natural products. Methods: The literature survey using PubMed was made manually in order to collect the natural product that exhibit anticancer activity but not or least toxic to normal cell, and were curated by in an open access central resource database. Result: The compound database provides opportunities for researchers to obtain various information required for the successful identification of pharmaceutically relevant substances. Application: The bioactive natural products with anticancer therapeutic potential are abundantly reported, but majority of them are toxic to normal cells too. All those novel natural product molecules failed to proceed towards further detailed research or to reach into clinical trial and pharmaceutical drug development and drug approval.
\end{abstract}

Keywords: Cancer, Database, Natural Products, Plants, Toxic, CSTNPD

\section{Introduction}

Cancer (-a very complex genetic or metabolic disease) is well-recognized as a global health problem ${ }^{1}$, accounts for approximately 7.6 million deaths (about $13 \%$ of all deaths or 1 in every 7 deaths) worldwide ${ }^{2,3}$. Billions of dollar invested on the advanced, sophisticated and multidisciplinary research works on the cancer has resulted into the identification of varieties of therapeutic targets of cancer as well as the development of vast number of anticancer drugs ${ }^{4}$ which have reduced the death rates owing to cancer during last two decades; however, the perfect drug to combat the cancer is still a nightmare ${ }^{5}$.

Further, the use of chemotherapy as well as the radiotherapy used for the treatment of cancer causes serious side effects ${ }^{6}$. The plant natural products have continuously being explored for the new leads in pharmaceutical development $^{7,8}$ including cancer ${ }^{9,4,10}$. The in vitro cell-based cytotoxicity assays of bioactivity-guided fractionation of plant extracts resulted into the varieties of alkaloids, flavonoids, 
polysaccharides, saponins and terpenoids, and others lead molecules, and have been documented as natural anticancer bioactive products ${ }^{11-15}$ which inhibits the cell proliferation mainly by inducing apoptosis ${ }^{13,16}$ or autophagy ${ }^{17,18}$ act through regulating immune function, and thus have considerably less side effects as compared to synthetic anticancer drug lead ${ }^{6}$. The reports of novel natural product toxic to various cancer cells are continuously coming ${ }^{19}$ resulted into the presence of voluminous biomedical literature, but such novel natural product molecules failed to proceed towards further detailed research or to reach into clinical trial and pharmaceutical drug development and drug approval because of the least or not having the cancer cell specific toxicity $^{20}$. The compound database provides opportunities for researchers to obtain various information required for the successful identification of pharmaceutically relevant substances $^{21}$. The natural compound online databases like SuperNatural ${ }^{22,23}$ CancerResource ${ }^{24,25}$, HerbIngredients' Targets $^{26}, \mathrm{NPACT}^{8}, \mathrm{TCMID}^{27}, \mathrm{TCMSP}^{28}$, CancerHSP ${ }^{29}$, Phytochemica ${ }^{30}$, NPCARE $^{31}$ or, NPASS ${ }^{32}$ exists that focuses on plant-based naturally occurring compounds; however, to our knowledge, online database resources related to cancer specific toxic natural products is lacking. Therefore, to capture the information regarding those plant based anticancer compounds exhibit anticancer activity but not or least toxic to normal cell, we have designed and developed an open access central online resource termed 'Cancer Specific Toxic Natural Products Database' (CSTNPD) currently hosted at http://www.cstnp.co.in.

\section{Data Collection}

The literature survey using PubMed were made manually in order to collect the natural product that exhibit anticancer activity but not or least toxic to normal cell. Overall, for each and every entry, in addition with submitter information (name of the submitter, affiliation and date), the brief information about the compound, source (novel/literature), reference, reference link and chemical structure of the compound in the form of the image have been curated with a unique ID of CSTNPD under the Tab 'Browse' (Figure 1).

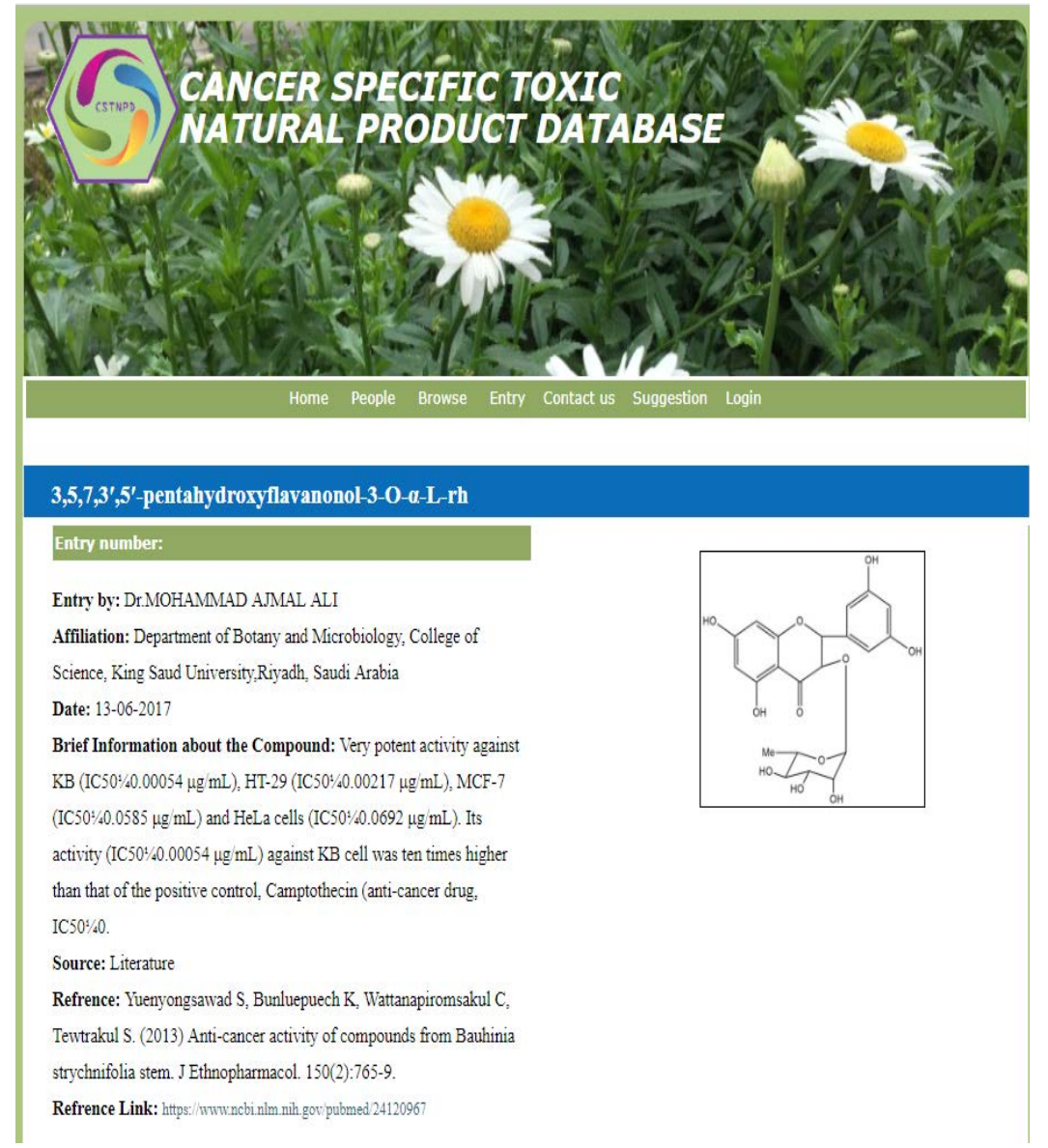

Figure 1. Screenshot of the Cancer Specific Toxic Natural Products Database' (CSTNPD) Web interface. 


\section{Architecture of the Database and Web Interface}

Once we gathered all the information associated to the specific compound we integrate the data in MYSQL, which is freely available open source Relational Database Management System (RDBMS), it functions at the backend. The web interface and the front end were built in PHP, HTML, and Java Script. We have built CSTNPD website on Apache HTPP Server with MYSQL server and PHP, HTML, and Java Script. We have used these Software's or technologies because these all technologies are platform independent and are open source software/technologies.

\section{Open Access Submission}

The main limitation in development of such databases is that it requires extensive literature search to generate entries and expand the database; therefore, development of such database need global support from the scientific community. Keeping this in mind, CSTNPD also offers an online facility of new submission.

The submitter can make entry of new compound information by filling the entry form. For the new submission, the detailed information of the submitter, Source (novel report by the submitter/literature/other), brief information of the compound, reference, reference link, Structure of the compound in the image form are required. The entries are then added to the database after successful validation.

\section{Availability}

The 'Cancer Specific Toxic Natural Products Database' (CSTNPD) is currently freely available at http://www. cstnp.co.in. To access the database, the user needs to register through email ID.

\section{Discussion}

The drugs discovery for any disease is a complex, costly and time taking endeavor. Furthermore, it is well know that only few number of drug candidate undergo for the clinical trial, and then at the last reached to patient after successfully clinical trial. 'In silico' studies such as molecular docking and molecular dynamics simulation are now become the basic component of the drug discovery process for variety of dis- ease including cancer ${ }^{33}$. The public and commercial databases storing information on chemical compounds allow scaffolds for the design and development novel drugs ${ }^{21}$. The database like 'CancerResource' (http://bioinformatics. charite.de/care) deals compound-target interaction; mRNA expression and mutation data from cancer genomics experiments ${ }^{25}$. Herb Ingredients' Targets (http://lifecenter. sgst.cn/hit/) curated herbal ingredients with the information protein target ${ }^{26}$. The 'SuperNatural' database (http:// bioinformatics.charite.de/supernatural) is a resource contains 3D structures and conformers of about 50,000 natural compound ${ }^{22}$. The natural products database 'Super Natural II' (http://bioinformatics.charite.de/supernatural) contains about the corresponding $2 \mathrm{~d}$ structures, physicochemical properties, predicted toxicity class and information of the potential vendors ${ }^{23}$. The 'Naturally Occurring Plant-based Anti-cancer Compound-Activity-Target database' (http:// crdd.osdd.net/raghava/npact/) plant derived natural compounds exhibiting anti-cancerous activity ${ }^{20}$. The present literature based online freely access database 'CSTNPD' (Cancer Specific Toxic Natural Products Database) contains toxicity information on several of natural product such UttrosideB, Quercetin, 3,5,7,3',5'-pentahydroxy flavanonol-3-O- $\alpha$-L-rhand 3,5,7-Trihydroxychromone3-O- $\alpha$-L-rhamnopyranoside. The compound Uttroside B isolated from the leaves of Solanumnigrum $\mathrm{L}$ is cytotoxic to the liver cancer cell line, HepG2 (IC50: $0.5 \mu \mathrm{M}$ ) but nontoxic to normal immortalized hepatocytes ${ }^{34}$. Quercetin $\left(3,3^{\prime}, 4^{\prime}, 5,7\right.$-pentahydroxy-flavone) (-a flavonoids occurs in fruits and Vegetables), induced cytotoxicity in leukemic cells and in breast cancer cells; however, its cytotoxicity to the normal cells was least or limited ${ }^{35}$. The compounds $3,5,7,3^{\prime}, 5^{\prime}$-pentahydroxyflavanonol-3-O- $\alpha$-L-rh and 3,5,7-Trihydroxychromone-3-O- $\alpha$-Lrhamnopyranoside isolated from stem and root of Bauhinia strychnifolia Craib (Fabaceae) shows very potent activity against KB, HT-29, MCF-7 and HeLa cells, but did not show cytotoxicity with normal cells at the concentration of $1 \mu \mathrm{g} / \mathrm{mL}^{36,37}$.

Moreover, the CSTNPD complements with the other database viz., SuperNatural ${ }^{22,23}$, CancerResource ${ }^{24,25}$, Herb Ingredients' Targets $^{26}$, NPACT ${ }^{20}$, TCMID $^{27}$, TCMSP $^{28}$, CancerHSP ${ }^{29}$, Phytochemica ${ }^{30}$, NPCARE ${ }^{31}$ or, NPASS $^{32}$ in providing the entry of the compounds exhibit anticancer activity but not or least toxic to normal cell, which will be nevertheless facilitate novel anticancer drug discovery, mechanism study, and in the development of in-silico tools and techniques. 


\section{Conclusions}

The compiled database as an open access central resource for cancer specific toxic natural products will provide opportunities for researchers to obtain various information required for the successful identification of pharmaceutically relevant substances for cancer. The bioactive natural products with anticancer therapeutic potential are abundantly reported, but majority of them are toxic to normal cells too; as a result, all those novel natural product molecules failed to proceed towards further detailed research or to reach into clinical trial and pharmaceutical drug development and drug approval.

\section{Acknowledgements}

The authors extend their appreciation to the Deanship of Scientific Research at King Saud University for funding the work through the research group project No RGPxxxxx.

\section{Disclosure}

The authors report no conflicts of interest in this work.

\section{References}

1. Wishart DS. Is Cancer a Genetic Disease or a Metabolic Disease? EBioMedicine. 2015; 2(6):478-9. https:// doi.org/10.1016/j.ebiom.2015.05.022 PMid:26288805 PMCid:PMC4535307

2. Cancer Facts \& Figures 2017. Available from: https://www. cancer.org/research/cancer-facts-statistics/all-cancer-factsfigures/cancer-facts-figures-2017.html. Date accessed: 2017.

3. Siegel RL, Miller KD, Jemal A. Cancer statistics. CA: A Cancer Journal for Clinicians. 2018; 68(1):7-30. https://doi. org/10.3322/caac.21442

4. Newman David J, Cragg GM. Natural Products as Sources of New Drugs from 1981 to 2014. Journal of Natural Products. 2016; 79(3):629-61. https://doi.org/10.1021/acs. jnatprod.5b01055 PMid:26852623

5. Hait WN. Anticancer drug development: the grand challenges. Nature Reviews Drug Discovery. 2010; 9(4):253-4. https://doi.org/10.1038/nrd3144 PMid:20369394

6. Huang CY, Ju DT, Chang CF, Muralidhar Reddy P, Velmurugan BK. A review on the effects of current chemotherapy drugs and natural agents in treating non-small cell lung cancer. Biomedicine (Taipei). 2017; 7(4):23. https:// doi.org/10.1051/bmdcn/2017070423

PMid:29130448 PMCid:PMC5682982

7. Baker DD, Chu M, Oza U, Rajgarhia V. The value of natural products to future pharmaceutical discovery. Natural Product Reports. 2007; 24(6):1225-44. https://doi. org/10.1039/b602241n PMid:18033577

8. Mangal M, Sagar P, Singh H, Raghava GP, Agarwal SM. NPACT: Naturally Occurring Plant-based Anti-cancer Compound-Activity-Target database. Nucleic Acids Research. 2013; 41:1124-9. https://doi.org/10.1093/nar/ gks1047 PMid:23203877 PMCid:PMC3531140

9. Douglas Kinghorn A, Chin YW, Swanson SM. Discovery of Natural Product Anticancer Agents from Biodiverse Organisms. Current Opinion in Drug Discovery and Development. 2009; 12(2):189-96. PMid:19333864 PMCid:PMC2877274

10. Nature is the best source of anticancer drugs: Indexing natural products for their anticancer bioactivity. Available from: https://www.ncbi.nlm.nih.gov/pubmed/29121120. Date accessed: 09/011/2017.

11. Harvey Alan L. Natural products in drug discovery. Drug Discovery Today. 2008; 13(19-20):894-901. https://doi. org/10.1016/j.drudis.2008.07.004 PMid:18691670

12. Nobili S, Lippi D, Witort E, Donnini M, Bausi L, Mini E, Capaccioli S. Natural compounds for cancer treatment and prevention. Pharmacological Research. 2009; 59(6):365-78. https://doi.org/10.1016/j.phrs.2009.01.017 PMid:19429468

13. Tan W, Lu J, Huang M, Li Y, Chen M, Wu G, Gong J, Zhong Z, Xu Z, Dang Y, Guo J, Chen X, Wang Y. Anti-cancer natural products isolated from chinese medicinal herbs. Chinese Medicine. 2011; 6(1):27. https://doi.org/10.1186/17498546-6-27 PMid:21777476 PMCid:PMC3149025

14. Joshi P, Vishwakarma RA, Bharate SB. Natural alkaloids as P-gp inhibitors for multidrug resistance reversal in cancer. European Journal of Medicinal Chemistry. 2017; 138:273-92. https://doi.org/10.1016/j.ejmech.2017.06.047 PMid:28675836

15. Majumder D, Das A, Saha C. Catalase inhibition an anti cancer property of flavonoids: A kinetic and structural evaluation. International Journal of Biological Macromolecules. 2017; 104:929-35. https://doi. org/10.1016/j.ijbiomac.2017.06.100 PMid:28663152

16. Simone F. Modulation of Apoptosis by Natural Products for Cancer Therapy. PlantaMedica. 2010; 76(11):1075-9. https://doi.org/10.1055/s-0030-1249961 PMid:20486070

17. Elaborating the Role of Natural Products-Induced Autophagy in Cancer Treatment: Achievements and Artifacts in the State of the Art. Available from: https://www.hindawi.com/ journals/bmri/2015/934207/. Date accessed: 2015.

18. Lin SR, Fu YS, Tsai MJ, Cheng H, Weng CF. Natural Compounds from Herbs that can Potentially Execute as 
Autophagy Inducers for Cancer Therapy. International Journal of Molecular Sciences. 2017; 18(7):1412. https://doi.org/10.3390/ijms18071412 PMid:28671583 PMCid:PMC5535904

19. Demain AL, Vaishnav P. Natural products for cancer chemotherapy. Microbial Biotechnology. 2011; 4(6):687-99. https://doi.org/10.1111/j.1751-7915.2010.00221.x PMid: 21375717 PMCid:PMC3815406

20. Lekphrom R, Kanokmedhakul S, Kanokmedhakul K. Bioactive styryllactones and alkaloid from flowers of Goniothalamus laoticus. Journal of Ethnopharmacology. 2009; 125(1):47-50. https://doi.org/10.1016/j. jep.2009.06.023 PMid:19573585

21. Fullbeck M, Michalsky E, Dunkel M, Preissner R. Natural products: sources and databases. Natural Product Reports. 2006; 23(3):347-56. https://doi.org/10.1039/B513504B PMid:16741583

22. SuperNatural: a searchable database of available natural compounds. Available from: https://www.ncbi.nlm.nih.gov/ pmc/articles/PMC1347494/. Date accessed: 01/01/2006.

23. Super Natural II a database of natural products. Available from: https:/www.ncbi.nlm.nih.gov/pmc/articles/ PMC4384003/. Date accessed: 28/01/2015.

24. CancerResource: a comprehensive database of cancerrelevant proteins and compound interactions supported by experimental knowledge. Available from: https://www. ncbi.nlm.nih.gov/pubmed/20952398. Date accessed: $39 / 01 / 2011$.

25. CancerResource--updated database of cancer-relevant proteins, mutations and interacting drugs. Available from: https://www.ncbi.nlm.nih.gov/pubmed/26590406. Date accessed: 04/01/2016.

26. HIT: linking herbal active ingredients to targets. Available from: https://www.ncbi.nlm.nih.gov/pubmed/21097881. Date accessed: 01/2011.

27. TCMID: traditional Chinese medicine integrative database for herb molecular mechanism analysis. Available from: https://www.ncbi.nlm.nih.gov/pubmed/23203875. Date accessed: 01/2013.
28. TCMSP: a database of systems pharmacology for drug discovery from herbal medicines. Available from: https://www.ncbi. nlm.nih.gov/pubmed/24735618. Date accessed: 16/04/2014.

29. CancerHSP: anticancer herbs database of systems pharmacology. Available from: https://www.ncbi.nlm.nih.gov/ pmc/articles/PMC4466901/. Date accessed: 05/06/2015.

30. Phytochemica: a platform to explore phytochemicals of medicinal plants. Available from: https://www.ncbi.nlm. nih.gov/pubmed/26255307. Date accessed: 08/08/2015.

31. NPCARE: database of natural products and fractional extracts for cancer regulation. Available from: https:// www.ncbi.nlm.nih.gov/pmc/articles/PMC5267755/. Date accessed: 05/01/2017.

32. NPASS: natural product activity and species source database for natural product research, discovery and tool development. Available from: https://www.ncbi.nlm.nih. gov/pubmed/29106619. Date accessed: 04/01/2018.

33. Stark JL, Powers R. Application of NMR and molecular docking in structure-based drug discovery. Topics in Current Chemistry. 2012; 326:1-34. https://doi. org/10.1007/128_2011_213 PMid:21915777

34. Evaluation of uttroside $B$, a saponin from Solanum nigrum Linn, as a promising chemotherapeutic agent against hepatocellular carcinoma. Available from: https://www. ncbi.nlm.nih.gov/pubmed/27808117. Date accessed: 03/11/2016.

35. Quercetin, a Natural Flavonoid Interacts with DNA, Arrests Cell Cycle and Causes Tumor Regression by Activating Mitochondrial Pathway of Apoptosis. Available from: https://www.ncbi.nlm.nih.gov/pubmed/27068577. Date accessed: 12/04/2016.

36. Yuenyongsawad S, Bunluepuech K, Wattanapiromsakul C, Tewtrakul S. Anti-cancer activity of compounds from Bauhinia strychnifolia stem. Journal of Ethnopharmacology. 2013; 150(2):765-9. https://doi. org/10.1016/j.jep.2013.09.025 PMid:24120967

37. Taraphdar AK, Roy M, Bhattacharya RK. Natural products as inducers of apoptosis: Implication for cancer therapy and prevention. Current Science. 2001; 80(11):1387-96. 